\title{
The Impact of Systematic Laparoscopic Skills and Suture Training on Laparoscopic Hysterectomy Outcomes in a Brazilian Teaching Hospital
}

\section{O impacto do treinamento laparoscópico sistematizado de habilidades e sutura nos resultados da histerectomia laparoscópica em hospital universitário brasileiro}

\author{
Anna Luiza Lobão Gonçalves ${ }^{1}{ }^{1}$ Helizabet Abdala Ayroza-Ribeiro ${ }^{1}$ Raquel Ferreira Lima ${ }^{1}$ \\ Aline Estefane Eras Yonamine ${ }^{1}$ Fabio Ohara ${ }^{1}$ Paulo Augusto Galvão Ayroza-Ribeiro ${ }^{1}$ \\ ${ }^{1}$ Gynecological Endoscopy and Endometriosis Sector, Department of \\ Obstetrics and Gynecology, Faculdade de Ciências Médicas, Santa \\ Casa de São Paulo, São Paulo, SP, Brazil \\ Address for correspondence Anna Luiza Lobão Gonçalves, Master, \\ Rua Cesário Motta Junior 61, 01221-020, São Paulo, SP, Brazil \\ (e-mail: dra.annaluiza@gmail.com).
}

Rev Bras Ginecol Obstet 2019;41:718-725.

\begin{abstract}
Objective To evaluate the impact of systematic laparoscopic skills and suture training (SLSST) on the total laparoscopic hysterectomy intra- and postoperative outcomes in a Brazilian teaching hospital.

Methods A cross-sectional observational study in which 244 charts of total laparoscopic hysterectomy (TLH) patients operated from 2008 to 2014 were reviewed. Patient-specific (age, parity, previous cesarean sections, abdominal surgeries and endometriosis) and surgery-related variables (hospital stay, operative time, uterine volume and operative complications) were analyzed in three different time-frame groups: 2008-09 (I-1) - TLHs performed by senior attending physicians; 2010-11 (I-2) TLHs performed by residents before the implementation of the SLSST program; and 2012-14 (I-3) - TLHs performed by residents after the implementation of the SLSST program.

Results A total of 244 TLH patients (mean age: 45.93 years) were included: 24 (I-1), 55 (I-2), and 165 (I-3). The main indication for TLH was uterine myoma (66.4\%). Group I-3 presented a decrease in surgical time compared to group I-2 $(p=0.010)$. Hospital stay longer than 2 days decreased in group $1-3$ compared to group I-2 $(p=0.010)$. Although we observed decreased uterine volume $\left(154.2 \mathrm{~cm}^{3}\right)$ in group I-2 compared to group I-1

Keywords

- hysterectomy

- laparoscopic surgery

- education

- suture training

$\left(217.8 \mathrm{~cm}^{3}\right)(p=0.030)$, logistic regression did not find any association between uterine volume and surgical time $(p=0.103)$.

Conclusion The total operative time for laparoscopic hysterectomy was significantly shorter in the group of patients (I-3) operated after the systematic laparoscopic skills and suture training was introduced in our hospital.
\end{abstract}

received

May 15, 2019

accepted

September 16, 2019
DOI https://doi.org/

10.1055/s-0039-1700587.

ISSN 0100-7203.
Copyright $\odot 2019$ by Thieme Revinter

Publicações Ltda, Rio de Janeiro, Brazil
License terms

(c) (1) 


\section{Resumo}

\section{Palavras-chave \\ - histerectomia \\ - cirurgia laparoscópia \\ - educação \\ - treinamento de sutura}

Objetivo Avaliar o impacto do treinamento laparoscópico sistematizado de habilidades e sutura (TLSHS) nos resultados intra e pós-operatórios da histerectomia laparoscópica em um hospital universitário brasileiro.

Métodos Estudo observacional transversal de revisão de 244 prontuários de pacientes submetidas a histerectomia total laparoscópica (HTL) operadas entre 2008 e 2014. Os fatores específicos das pacientes (idade, paridade, cesariana prévia, cirurgias abdominais, e endometriose) e as variáveis relacionadas à cirurgia (tempo de hospitalização, tempo de cirurgia, volume uterino e complicações operatórias) foram analisados em três grupos temporais: 2008-09 (I-1) - HTLs realizadas por médicos experientes; 2010-11 (I-2) - HTLs realizadas por residentes sem TLSHS; 2012-2014 (I-3) - HTLs realizadas por residentes após a implementação do TLSHS.

Resultados Um total de 244 pacientes submetidas a HTLs foram incluídas (média de idade de 45,93 anos): 24 operadas no período I1, 55 no I2, e 165 no I3. A principal indicação para HTL foi mioma uterino (66,4\%). O grupo I-3 apresentou diminuição no tempo cirúrgico quando comparado ao grupo I-2 $(p=0,010)$. Hospitalização superior a 2 dias diminuiu no grupo I-3 comparado ao grupo I-2 $(p=0,010)$. Apesar de observarmos diminuição no volume uterino dos pacientes do grupo $1-2\left(154,2 \mathrm{~cm}^{3}\right)$ em comparação com os do grupo $\mathrm{l}-1\left(217,8 \mathrm{~cm}^{3}\right)(p=0,030)$, a regressão logística não revelou associação entre volume uterino e tempo cirúrgico $(p=0,103)$.

Conclusão O tempo cirúrgico na HTL foi significativamente menor no grupo de pacientes submetidas à cirurgia após a implantação do TLSHS em nosso hospital.

\section{Introduction}

Laparoscopy-assisted hysterectomy has evolved as an alternative to conventional open surgery since the end of the twentieth century. ${ }^{1}$ It uses cameras and specific instruments to remove the uterus, the fallopian tubes, and/or the ovaries through a minimally-invasive trans-vaginal access. ${ }^{2,3}$ The procedure is called total laparoscopic hysterectomy (TLH) when hemostatic clamping of the uterine vessels, resection of the uterosacral and cardinal ligaments, and colporrhaphy are all performed through a minimally-invasive video-assisted approach. ${ }^{3}$ The benefits of TLH are diminished postoperative pain, lower use of opioid analgesics, shorter hospital stay, early rehabilitation and return to work, minimal blood loss, enhanced visualization of intra-abdominal structures, which minimizes the risk of iatrogenic lesion to bladder and ureters, and lower rate of short- and long-term complications. ${ }^{4-6}$ Additonally, the intrafascial dissection technique preserves the vaginal apex support structures, maintaining vaginal length. ${ }^{6-9}$

However, TLH is not widespread in many countries. ${ }^{5,7,10-12}$ Data from the Brazilian Unified Healthcare System reveals only 2,947 laparoscopic procedures out of 932,382 hysterectomies performed from 2008 to $2017 .^{13}$ Developed countries like the United States and England estimate that $20 \%$ to $30 \%$ of hysterectomies are laparoscopic-assisted. ${ }^{10,14}$ The major struggle regarding laparoscopic surgery expansion has been to train new surgeons. The long learning curve to achieve proficiency in two-dimension screen vision, camera navigation, hand-eye coordination, and psychomotor skills to handle laparoscopic tools with dexterity conflict with a limited number of procedures and professionals in teaching hospitals with scarce resources. ${ }^{7,12,15,16}$ On the other hand, increased demand for laparoscopic procedures in private health systems pressure junior surgeons to take up complex cases they may not be proficient to deal with, resulting in lower surgical performances and increased morbidity and mortality. ${ }^{15,17}$

Laparoscopic psychomotor skills must be preliminarily acquired by practicing on specific validated training models outside the operating room. ${ }^{15-17}$ Similar to a video game, training platforms enable the repetitive practice of standard laparoscopic tasks. They also evaluate performance objectively, and provide feedback to the trainees. ${ }^{18}$ Simulators were proven to shorten surgical time and improve perioperative morbidity in TLH procedures, ${ }^{19}$ and they potentially reduce the learning curve compared to traditional surgical teaching methods. ${ }^{20}$ Current surgical practice regulations demand a controlled, standardized and validated training program for new laparoscopic surgeons, such as the "Winners" program in Europe and the American College of Obstetricians and Gynecologists (ACOG) Fundamentals of Laparoscopic Surgery (FLS) program, in the US. ${ }^{15}$ In an effort to validate an implemented standardized laparoscopic training in Brazil, the present study evaluated the impact of the systematic laparoscopic skill and suture training (SLSST) on the outcomes of TLH performed in a teaching hospital (Santa Casa de Misericórdia de São Paulo, in the city of São Paulo, Brazil) from 2008 to 2014. We hypothesized that the SLSST would have a positive impact on the intra- and postoperative outcomes of TLH. 


\section{Methods}

The present research was approved by the Ethics in Human Research Committee and Institutional Review Board of Santa Casa de Misericórdia de São Paulo (under number: 14945313.8.0000.5479)

We conducted a cross-sectional observational study in which 610 charts of patients submitted to hysterectomy at Santa Casa de Misericórdia de Sãoo Paulo from 2008 to 2014 were reviewed. All TLHs were included in the study, corresponding to $40 \%$ (244) of the procedures. The exclusion criteria were: subtotal or partial hysterectomy; hysterectomies associated with open rectosigmoidectomy and/or partial cystectomy due to endometriosis; and malignant diseases requiring total hysterectomy with open retroperitonial exploration.

Patient-specific (age, parity, previous cesarean sections, abdominal surgeries and endometriosis) and surgery-related (hospital stay, operative time, rate of conversion to open procedure, uterine volume, intra- and postoperative complications) variables were analyzed.

The postoperative complications were divided according to the Clavien-Dindo (C-D) classification (-Table 1), which was created in 1992 (by Clavien PA, Dindo D and Demartines $\mathrm{N}$ at University Hospital of Zurich, Zurich, Switzerland) is widely used, and is based on the type of therapy needed to correct the complication. ${ }^{21}$

In our institution, we receive every year 4 first-year residents (PGY-4 OB/GYN) of the Gynecologic Endoscopy and Endometriosis Fellowship Program, and 2 second-year residents (PGY-5 OB/GYN) of the Gynecologic Endoscopy and Endometriosis Fellowship Program. The surgeries were divided into three different time-frame groups reflecting distinct benchmarks of the SLSST curriculum implemented for the Gynecology Endoscopy and Endometriosis Fellowship Program: 2008-09 (I-1) - TLH performed by senior attending physicians with more than 5 years of experience in laparoscopic surgery; 2010-11 (I-2) - TLH performed by the new firstyear residents (PGY-4 OB/GYN) before the implementation of the SLSST, supervised by senior physicians; and 2012-14 (I-3) -TLH performed by the new first-year residents (PGY-4 OB/ GYN) after the implementation of the SLSST. The surgeries performed during the first 14 weeks of the SLSST (dominant hand training period) were excluded from this group. The surgeries were assisted and supervised by a second-year (PGY$5 \mathrm{OB} / \mathrm{GYN}$ ) resident who was also submitted to the same training program, but at the end of the previous year.

An average of 7 TLHs per PGY-4/year was observed in the I- 2 group, and an average of 14 TLHs per PGY-4/year was observed in the I-3 group.

\section{Standard Total Laparoscopic Hysterectomy}

The intrafascial technique has been standardized to all TLHs performed by the Gynecologic Endoscopy and Endometriosis Group of Santa Casa de Misericórdia de São Paulo since 2008. The same standard steps are performed in the same order for every TLH.

1. Position on the gynecological table with the legs on the gaiters, the buttocks $5 \mathrm{~cm}$ above the table, and arms on jambs along the body, asepsis/antisepsis, followed by late bladder catheterization using a no. 14 Foley catheter, hysterometry and uterine manipulator placement.

2. Intra-umbilical incision (longitudinal or arch-shaped), abdominal puncture using a Veress needle followed by safety maneuvers (dual recoil test, saline infusion-suction test, and pendant drop test), peritoneum distention with $\mathrm{CO}_{2}$ (6 mmHg to $20 \mathrm{mmHg}$ ), assessment of abdominal distension symmetry, and loss of liver solidness to percussion sign.

3. Introduction of the intra-umbilical trocar and cavity inventory to assess puncture accidents and adherences. Low pneumoperitoneum pressure to $14 \mathrm{mmHg}$, Trendelemburg position, and establishment of accessory portals using 5-mm trocars (-Figure $\mathbf{1}$ ).

4. Left round ligament styptic section, dissection of the anterior peritoneum from the broad ligament to the

Table 1 Clavien-Dindo classification

\begin{tabular}{|l|l|}
\hline Grades & Definition \\
\hline Grade I & $\begin{array}{l}\text { Any deviation from the normal postoperative course without the need for pharmacological treatment or surgical, } \\
\text { endoscopic and radiological interventions. } \\
\text { The allowed therapeutic regimens are: drugs as antiemetics, antipyretics, analgesics, diuretics and electrolytes and } \\
\text { physiotherapy. This grade also includes wound infections opened at the bedside. }\end{array}$ \\
\hline Grade II & $\begin{array}{l}\text { Requiring pharmacological treatment with drugs other than those allowed for grade I complications. Blood } \\
\text { transfusions and total parenteral nutrition are also included. }\end{array}$ \\
\hline Grade III & Requiring surgical, endoscopic or radiological interventions. \\
\hline IIIa & Intervention not under general anesthesia.. \\
\hline IIIb & Intervention under general anesthesia \\
\hline Grade IV & $\begin{array}{l}\text { Life-threatening complications (including central nervous system complications)* requiring management at } \\
\text { intermediate care or intensive care unit. }\end{array}$ \\
\hline IVa & Single-organ dysfunction (including dialysis). \\
\hline IVb & Multiple-organ dysfunction. \\
\hline Grade V & Death of a patient. \\
\hline
\end{tabular}

Note: *Brain hemorrhage, ischemic stroke, subarachnoid bleeding, but excluding transient ischemic attacks. 


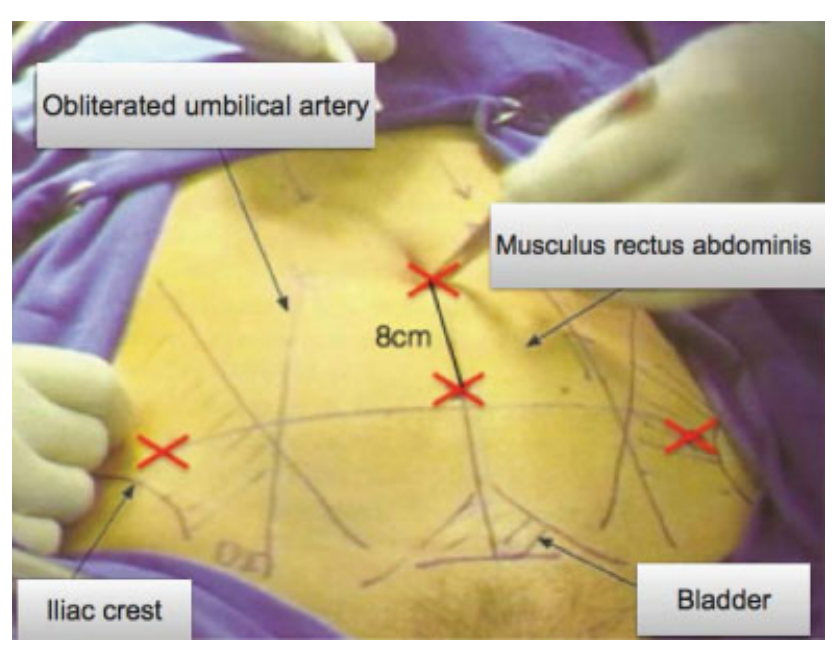

Fig. 1 Locations of the portals.

bladder reflex, and establishment of an avascular plane left uterus-ovarian ligament styptic section, followed by left salpingectomy. If left oophorectomy is required, identify the left ureter and perform the styptic section of the infundibulum (-Figure 2).

5. Dissect the posterior peritoneum from the broad ligament of the uterus to the sacrouterine ligament and perform the styptic section of the left uterine vessels ( - Figure $3 \mathbf{A}$ ).

6 . The same sequence ( 4 and 5 ) is then repeated on the right side.

7. Bladder retracted inferiorly (-Figure 3B), colpotomy using a monopolar cautery ( - Figure $3 \mathbf{C}$ ), and transvaginal removal of the uterus employing a vaginal liner.

8. Place a vaginal tampon to hold the pneumoperitoneum, followed by trans-peritoneal colporrhaphy using no. 0 Vicryl (polyglactin 910 manufactured by Ethicon Inc., a subsidiary of Johson and Johnson) with x-shaped stitches at the angles of the vagina and continuous stitches in the center ( - Figure 3D).
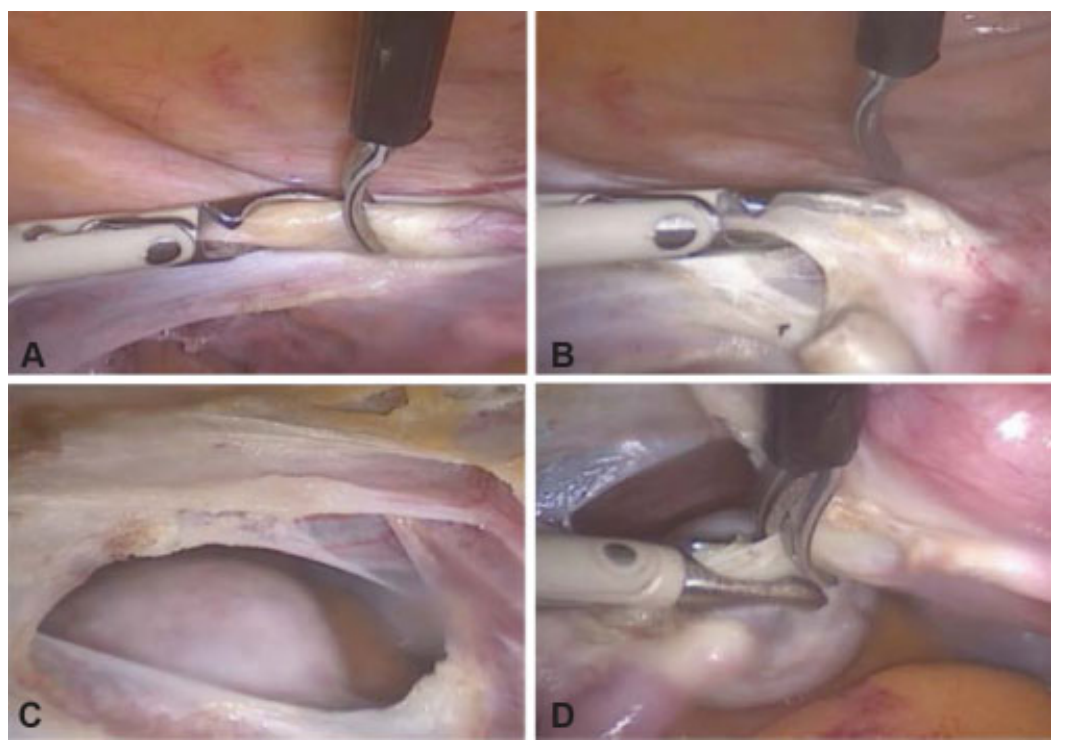

9. Review the hemostasis, remove the vaginal tampon, perform the suction of the pneumoperitoneum, return to horizontal decubitus, and perform the intra-umbilical aponeurosis suture and trocar incision closure.

\section{Systematic laparoscopic skills and suture training (SLSST)}

The training was implemented to the curriculum of the Gynecologic Endoscopy and Endometriosis Fellowship Program in 2012. Based on the Romeo Gladiator Rule seven-week activities ${ }^{22}$ (-Table 2), the SLSST consisted of a 21week (4 hours per week) hands-on training at the experimental laboratory. Each week, the residents had to practice the scheduled exercise for a minimum of 4 hours. The core exercises were performed with the dominant hand on the lateral trocar for the initial 7 weeks of the program, followed by the dominant hand on the central trocar from the 8 th to the 14 th weeks, and the non-dominant hand on the lateral trocar from the 15 th to the 21 st weeks.

\section{Statistical Analysis}

All data were recorded in Excel (Microsoft Corp., Redmond, WA, US), version 14.5.7, spreadsheets, and the statistical analyses were performed using in the Statistical Package for the Social Sciences (SPSS, IBM Corp., Armonk, NY, US) software, version 22 . The calculation of the sample size was estimated based on a pilot group of 10 patients obtained from the first period of time (I-1). Using a standard deviation of 50 minutes and an estimated difference of 30 minutes, a sample of 34 patients was suggested to obtain a study power of $80 \%$ with a significance of $5 \%$. The Kolmogorov-Smirnov test was performed for each independent variable to determine normal distribution. The Chi-squared test was used to compare parametric variables. The Student $t$-test was used to compare parametric continuous variables, and logistic regression was performed to determine the association between the variables. Data are shown as mean \pm standard

Fig. 2 (A) Hemostatic section of the left round ligament; (B) dissection of the left broad ligament of the uterus; (C) left avascular window; (D) hemostatic section of the left uterus-ovarian ligament. 


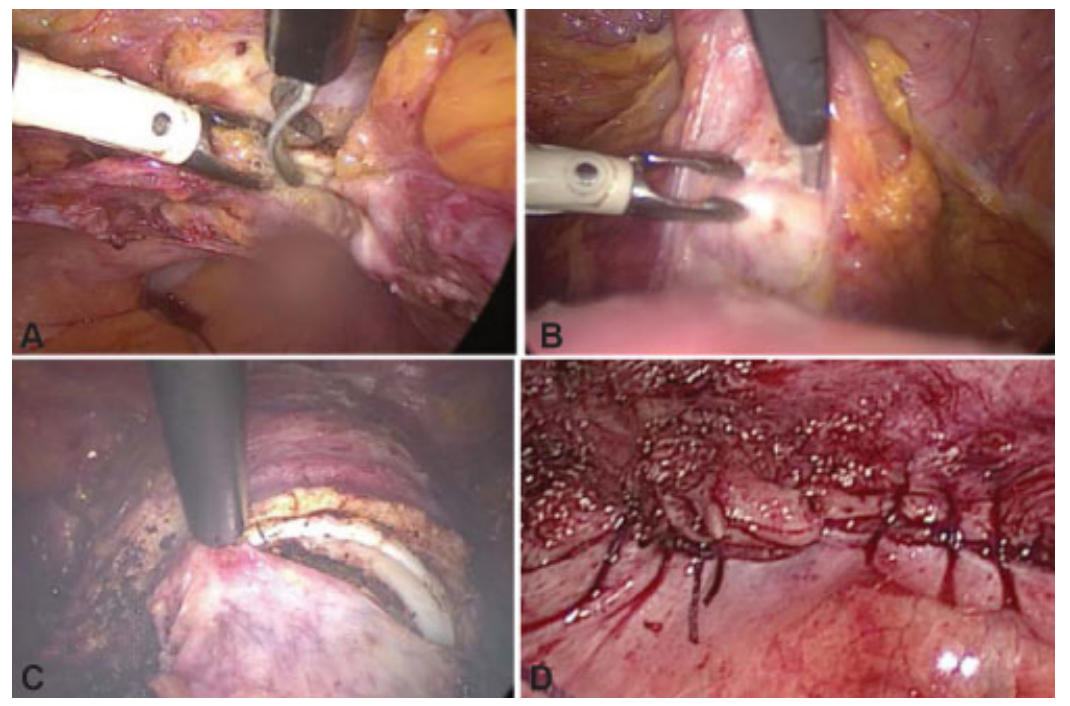

Fig. 3 (A) Section of the left uterine vessels; (B) lower retraction of the bladder; (C) colpotomy; (D) colporrhaphy.

Table 2 Systematic laparoscopic skills and suture training core program

\begin{tabular}{|l|l|}
\hline Week & Exercises \\
\hline 1st & Gladiator navigation \\
\hline 2nd & Gladiator with knot technique \\
\hline 3rd & Needle and guidelines \\
\hline 4th & $\begin{array}{l}\text { Check-cross, deep and shallow stitches } \\
\text { (staggering) }\end{array}$ \\
\hline 5th & Simple stitch with knot (number and resistance) \\
\hline 6th & $\begin{array}{l}\text { Vaginal apex: x-shaped stitches, continuous suture } \\
\text { right to left and left to right }\end{array}$ \\
\hline 7th & Myomectomy sutures and invaginating stitches \\
\hline $\begin{array}{l}\text { 1st to 7th: Dominant hand on lateral trocar } \\
\text { 8th to 14th: Dominant hand on central trocar* } \\
\text { 15th to 21st: Non-dominant hand on lateral trocar* }\end{array}$ \\
\hline
\end{tabular}

Notes: Training based on the Romeo Gladiator Rule. ${ }^{22}$ *Same exercise sequence as weeks 1 to 7 .

deviation (SD). Values of $p<0.05$ were considered significant for the inferential analysis.

\section{Results}

We included 244 cases of TLH in the study: 24 operated in 2008-09 (I-1); 55 in 2010-11 (I-2); and 165 in 2012-14 (I-3). The increase in TLHs performed per year at our hospital between periods I- 1 and I-2 was of $129 \%$, and between I-2 and $\mathrm{I}-3$, it was of $100 \%$. The mean age of the patients was $45,93 \pm 8,37$ (SD) years. Patient-specific variables are reported on table 3 . The procedures performed together with TLH, like salpingectomy, oophoroplasty/oophorectomy, and deep endometriosis are shown in table 3.

The clinical indications for TLH were mainly uterine myoma (66.4\%) and endometriosis (16.4\%). Only two cases were diagnosed with malignant disease, and they were referred to the gynecologic oncology service after surgery.
Table 3 Patient-specific variables and procedures performed

\begin{tabular}{|l|l|l|l|}
\hline Features & & $\mathbf{n}$ & $\%$ \\
\hline Parity & 0 & 22 & $9.0 \%$ \\
\cline { 2 - 4 } & 1 & 29 & $11.9 \%$ \\
\cline { 2 - 4 } & $\geq 2$ & 193 & $79.1 \%$ \\
\hline $\begin{array}{l}\text { Previous cesarean } \\
\text { section }\end{array}$ & 117 & $48.0 \%$ \\
\hline Endometriosis & 44 & $18.0 \%$ \\
\hline $\begin{array}{l}\text { Previous abdominal sur- } \\
\text { geries } \\
\text { (including cesarean } \\
\text { section) }\end{array}$ & 184 & $75.4 \%$ \\
\hline $\begin{array}{l}\text { Total laparoscopic hys- } \\
\text { terectomy only }\end{array}$ & 102 & $41.8 \%$ \\
\hline plus salpingectomy & 76 & $31.1 \%$ \\
\hline plus ovarian surgery & 35 & $14.3 \%$ \\
\hline plus endometriosis & 24 & $9.8 \%$ \\
\hline plus others procedures & 07 & $2.9 \%$ \\
\hline
\end{tabular}

Comparing the three groups studied, we observed a significant difference in the number of previous cesarean sections, previous abdominal surgeries, rate of conversion to open surgery, and hospital stay longer than 2 days (-Table 4). Out of 244 TLHs, 3 were converted to open laparotomy due to high uterine volume, and 1 required an open vaginal route. The overall complication rate was of 5.7\%: $2.0 \%$ intraoperative and $3.7 \%$ postoperative complications.

We observed 6 intraoperative complications ( 1 internal iliac artery lesion, 1 acute respiratory failure, 2 sutured bladder lesions and 2 vaginal wall lacerations) and 11 postoperative complications (1 left iliac fossa seroma - C-D II; 1 umbilical hernia - C-D IIIb; 1 wall endometrioma - C-D IIIb; 2 vaginal dome granulomas - C-D IIIb; 1 buckling in the distal left ureter with loss renal function - C-D Iva; 1 intraperitoneal vesical fistula - C-D IIIa; 1 vaginal dome bleeding - C-D IIIb; 1 urinary 
The Impact of Systematic Laparoscopic Skills and Suture Training Gonçalves et al. 723

Table 4 Clinical indications and associated variables stratified by time period

\begin{tabular}{|c|c|c|c|c|}
\hline & $\begin{array}{l}2008-09 \\
(I-1)\end{array}$ & $\begin{array}{l}2010-11 \\
(I-2)\end{array}$ & $\begin{array}{l}2012-14 \\
(I-3)\end{array}$ & $p$-value \\
\hline Myomatosis & $70.8 \%$ & $56.4 \%$ & $73.5 \%$ & 0.52 \\
\hline Endometriosis & $12.5 \%$ & $20.0 \%$ & $18.0 \%$ & 0.72 \\
\hline $\begin{array}{l}\text { Previous cesarean } \\
\text { section }\end{array}$ & $37.5 \%$ & $32.7 \%$ & $54.5 \%$ & 0.02 \\
\hline Comorbidities & $50.0 \%$ & $56.3 \%$ & $55.1 \%$ & 0.86 \\
\hline $\begin{array}{l}\text { Previous abdominal } \\
\text { surgeries }\end{array}$ & $45.8 \%$ & $60.0 \%$ & $69.7 \%$ & 0.03 \\
\hline Conversion & $4.1 \%$ & $1.8 \%$ & $1.2 \%$ & 0.04 \\
\hline $\begin{array}{l}\text { Hospital stay } \\
>2 \text { days }\end{array}$ & $29.1 \%$ & $49 \%$ & $18.1 \%$ & 0.01 \\
\hline $\begin{array}{l}\text { Intraoperative } \\
\text { complications }\end{array}$ & $0.0 \%$ & $3.6 \%$ & $2.4 \%$ & 0.52 \\
\hline $\begin{array}{l}\text { Postoperative } \\
\text { complications }\end{array}$ & $8.3 \%$ & $3.6 \%$ & $4.2 \%$ & 0.21 \\
\hline Clavien-Dindo $^{21}-\mathrm{I}$ & $0.0 \%$ & $0.0 \%$ & $0.0 \%$ & \\
\hline Clavien-Dindo - II & $0.0 \%$ & $0.0 \%$ & $2,4 \%$ & \\
\hline Clavien-Dindo - IIla & $0.0 \%$ & $0.0 \%$ & $0,6 \%$ & \\
\hline Clavien-Dindo - IIIb & $8,3 \%$ & $1,8 \%$ & $1,2 \%$ & \\
\hline Clavien-Dindo - IVa & $0.0 \%$ & $1,8 \%$ & $0.0 \%$ & \\
\hline Clavien-Dindo - IVb & $0.0 \%$ & $0.0 \%$ & $0.0 \%$ & \\
\hline Clavien-Dindo - V & $0.0 \%$ & $0.0 \%$ & $0.0 \%$ & \\
\hline
\end{tabular}

Note: Chi-squared statistical significance $(p<0.05)$.

retention - C-D II; 1 paralytic ileus - C-D II; and 1 postlumbarpuncture headache - C-D II).

We observed a decrease in uterine volume in group I-2 compared to group I-1: $217.8 \mathrm{~cm}^{3}$ and $154.2 \mathrm{~cm}^{3}$ respectively $(p=0.03)$. There was no difference in the uterine volume between groups $\mathrm{I}-2 / \mathrm{I}-3$ and $\mathrm{I}-1 / \mathrm{I}-3$. The operative time was longer in group I-2 when compared to group I-3 $(\mathrm{p}=0.01)$; there was no difference between groups I-1/I-2 and I-1/I-3 ( - Table 5). The logistic regression showed an association between uterine volume and baseline uterus disease $(p=0.02)$, comorbidities $(p=0.03)$, and type of surgery performed $(p<0.001)$. The operative time showed association with baseline uterus disease $(p=0.001)$, hospital stay $>2$ days $(p=0.002)$, endometriosis $(p=0.002)$, and intraoperative complications $(p=0.013)$. No significant association was found between uterine volume and operative time $(p=0.10)$ ( - Table 6 ).

\section{Discussion}

The data confirmed our hypothesis that the SLSST would have a significant impact on TLH outcomes. The procedures per-
Table 6 Logistic regression results

\begin{tabular}{|l|l|}
\hline Associations & $p$-value \\
\hline Uterine volume $\left(\mathrm{cm}^{3}\right) \times$ baseline uterus disease & $p=0.02$ \\
\hline Comorbidities & $p=0.03$ \\
\hline Type of surgery performed & $p<0.001$ \\
\hline Operative time (min) x baseline uterus disease & $p=0.001$ \\
\hline Hospital stay $>$ 2days & $p=0.002$ \\
\hline Endometriosis & $p=0.002$ \\
\hline Intraoperative complications & $p=0.013$ \\
\hline Uterine volume $\left(\mathrm{cm}^{3}\right)$ x operative time $(\mathrm{min})$ & $p=0.10$ \\
\hline
\end{tabular}

Note: Statistical significance $(p<0.05)$.

formed by the SLSST-trained residents (group I-3) presented a reduction in operative time, length of hospital stay and conversion, reinforcing that a systematic training program can shorten the long learning curve, improve performance, and promote safe laparoscopic surgical practice in a teaching hospital. ${ }^{23}$ Technique standardization for TLH contributed to make the surgical outcomes comparable regardless of the surgeon who performed the procedure, and made the training process easier for the residents, who were no longer exposed to multiple technique variations.

We observed an increasing number of TLHs during the time-frames analyzed in the present study. The mean annual number of procedures more than tripled after the implementation of the training program. The complexity of the surgeries also increased, with bilateral salpingectomy becoming routine in 2013, but it did not increase the surgical time, hospital stay, or the complication rates. The bilateral salpingectomy became routine for all TLHs in order to decrease the risk of ovarian cancer. ${ }^{24}$ These findings may be related to an increased confidence and proficiency in performing more complex laparoscopic procedures after the training program. When analyzing the hospital stay for patients submitted to TLH, one should consider quantitative data or a qualitative approach. Considering that the majority of the patients were discharged between the first and second postoperative days, we preferred to use qualitative data and a cutoff of two days of hospitalization. The length of our hospital stay was consistent with the current literature, and the rate of complications was half of those reported in the literature. ${ }^{25}$ We found higher prevalence rates of previous cesarean sections (48\%) and endometriosis (18\%) than those reported in the literature, ${ }^{23,26}$ which may be related to

Table 5 Uterine volume and operative time by group

\begin{tabular}{|c|c|c|c|}
\hline & $\begin{array}{l}2008-09 \\
(I-1)\end{array}$ & $\begin{array}{l}2010-11 \\
\mathrm{l}-2\end{array}$ & $\begin{array}{l}2012-14 \\
\mathrm{I}-3\end{array}$ \\
\hline Uterine volume $\left(\mathrm{cm}^{3} ;\right.$ mean \pm standard deviation) & $217,8 \pm 159,5$ & $154,2 \pm 95,9^{*}$ & $180,8 \pm 91,4$ \\
\hline Operative time (min; mean \pm standard deviation) & $219,8 \pm 50,0$ & $228,8 \pm 89,1$ & $204,5 \pm 51,9^{* *}$ \\
\hline
\end{tabular}

Notes: $t$-test statistical significance $(p<0.05) ;{ }^{*}$ I-1 versus I-2: $p=0.03 ;{ }^{* *} \mathrm{I}-2$ versus I-3: $p=0.01$. 
the extraordinary number of cesarean sections performed in Brazil, ${ }^{25}$ and to the fact that our hospital is a center of excellence for endometriosis care.

The present study did not find an association between uterine volume and operative time, neither between uterine volume and rate of complications. Our trained residents were able to significantly reduce TLH operative time in about 25 minutes, despite the fact that they resected a higher volume of uteri than the non-trained residents, suggesting that adequate training provided time-efficient abilities to young surgeons.

The traditional apprentice-tutor model is no longer valid to develop all skills necessary in gynecological surgery; the complexity of modern surgery has increased the demands and challenges to surgical education and the quality control. $^{27}$ Simulators motivate residents through the journey of proficiency in laparoscopy. ${ }^{28}$ The positive impact that simulator-acquired skills have on real surgeries was published in a recent systematic review. ${ }^{19}$ A positive relationship between systematic training in simulators and reduced operative time and complications were also reported in cases of bariatric and urologic laparoscopic surgery. ${ }^{29,30}$ In a Turkish study, Asoglu et $\mathrm{al}^{31}$ concluded that a simulator lab improves the outcomes of hysterectomy performed at a teaching institution, and may play an adjunct role in developing the resident's surgical skills; the results found by them are in line with the findings of our study.

In the present study, repetitive practice in simulators enabled the fellows to improve their psychomotor skills without the fear of making mistakes that could had been fatal in an actual surgery. The mistakes were analyzed by tutors who provided feedback and guided the residents to overcome obstacles. Tutorship in a stress-free environment translated into faster, safer and efficient surgical performance even for more experienced attending physicians. ${ }^{32}$ Many countries have established systematic training on simulators as requirements for laparoscopic surgeons. ${ }^{33}$ The present study was the initial step to validate a laparoscopic training program in Brazil. Our model may stimulate other academic hospitals to expand their proficiency laparoscopic skills, serving a bridge to a safe and effective full practice of in vivo laparoscopy.

Our study had several limitations. The cross-sectional design did not enable us to establish a temporal relationship between the training and surgical outcomes, or to determine if the experience of the surgeon measured by the number of TLHs previously performed had any influence over the surgical outcomes. Moreover, the substantial difference in the number of TLHs among the groups, and the variable skill levels of the senior attending physicians whose surgeries were included in group I-1 may be possible biases. Further prospective studies may define the number of previous TLHs necessary to reduce complications. On the other hand, the present study was, to our knowledge, this first clinical study to apply and evaluate the interference of the Romeo Gladiator training method on the outcomes of a surgical procedure.

\section{Conclusion}

The operative time for TLH was significantly shorter in the group of patients operated after the SLSST was introduced in our hospital.

\section{Contributors}

All authors contributed with the project and the interpretation of data, the writing of the article, the critical review of the intellectual content, and with the final approval of the version to be published.

Conflict of Interests

The authors have none to disclose.

\section{References}

1 Arbogast JD, Welch RA, Riza ED, Ricaurte EL, Pieper DR. Laparoscopically assisted vaginal hysterectomy appears to be an alternative to total abdominal hysterectomy. JLaparoendosc Surg 1994;4(03):185-190

2 Reich H. New techniques in advanced laparoscopic surgery. Baillieres Clin Obstet Gynaecol 1989;3(03):655-681

3 Ng CC, Chern BS. Total laparoscopic hysterectomy: a 5-year experience. Arch Gynecol Obstet 2007;276(06):613-618. Doi: 10.1007/s00404-007-0385-6

4 Chapron C, Laforest L, Ansquer Y, et al. Hysterectomy techniques used for benign pathologies: results of a French multicentre study. Hum Reprod 1999;14(10):2464-2470. Doi: 10.1093/humrep/ 14.10.2464

5 Chapron CM, Dubuisson JB, Ansquer Y. Is total laparoscopic hysterectomy a safe surgical procedure? Hum Reprod 1996;11 (11):2422-2424. Doi: 10.1093/oxfordjournals.humrep.a019128

6 Hohl MK, Hauser N. Safe total intrafascial laparoscopic (TAIL) hysterectomy: a prospective cohort study. Gynecol Surg 2010;7 (03):231-239. Doi: 10.1007/s10397-010-0569-0

7 Chapron C, Dubuisson JB. Ureteral injuries after laparoscopic hysterectomy. Hum Reprod 2000;15(03):733-734. Doi: 10.1093/humrep/15.3.733

8 Shwayder JM. The learning curve for laparoscopically assisted vaginal hysterectomy/laparoscopic hysterectomy. JAm Assoc Gynecol Laparosc 1994;1(4, Part 2):S33

9 Cavalli N, Sória HL, Galletto D, Sória-Vieira S, Bandeira CP, Fagundes DJ. Histerectomia vaginal assistida por videolaparoscopia associada à técnica intrafascial (HVALi) em 579 operações. Rev Bras Videocir 2003;1:128-134

10 Einarsson JI, Matteson KA, Schulkin J, Chavan NR, Sangi-Haghpeykar $\mathrm{H}$. Minimally invasive hysterectomies-a survey on attitudes and barriers among practicing gynecologists. J Minim Invasive Gynecol 2010;17(02):167-175. Doi: 10.1016/j.jmig.2009.12.017

11 Cosson M, Lambaudie E, Boukerrou M, Querleu D, Crépin G. Vaginal, laparoscopic, or abdominal hysterectomies for benign disorders: immediate and early postoperative complications. Eur J Obstet Gynecol Reprod Biol 2001;98(02):231-236

12 Sória HLZ, Fagundes DJ, Sória-Vieira S, Cavalli N, Santos CRC. [Hysterectomy and benign gynecological diseases: what has been performed in Medical Residency in Brazil?] Rev Bras Ginecol Obstet 2007;29:67-73. Doi: 10.1590/S0100-72032007000200002

13 Ministério da Saúde. Procedimentos Hospitalares do SUS - Por Local de Internação - Brasil.2017http://tabnet.datasus.gov.br/cgi/ tabcgi.exe?sih/cnv/qiuf.def. Accessed April 29, 2017.

14 Sculpher M, Manca A, Abbott J, Fountain J, Mason S, Garry R. Cost effectiveness analysis of laparoscopic hysterectomy compared with standard hysterectomy: results from a randomised trial. BMJ 2004;328(7432):134. Doi: 10.1136/bmj.37942.601331.EE 
15 Campo R, Molinas CR, De Wilde RL, et al. Are you good enough for your patients? The European certification model in laparoscopic surgery. Facts Views Vis ObGyn 2012;4(02):95-101

16 Takeda J, Kikuchi I, Kono A, Ozaki R, Kumakiri J, Takeda S. Efficacy of short-term training for acquisition of basic laparoscopic skills. Gynecol Minim Invasive Ther 2016;5:112-115. Doi: 10.1016/j. gmit.2015.06.001

17 Ahlberg G, Enochsson L, Gallagher AG, et al. Proficiency-based virtual reality training significantly reduces the error rate for residents during their first 10 laparoscopic cholecystectomies. Am J Surg 2007;193(06):797-804. Doi: 10.1016/j.amjsurg.2006.06.050

18 Sroka G, Feldman LS, Vassiliou MC, Kaneva PA, Fayez R, Fried GM. Fundamentals of laparoscopic surgery simulator training to proficiency improves laparoscopic performance in the operating room-a randomized controlled trial. Am J Surg 2010;199(01): 115-120. Doi: 10.1016/j.amjsurg.2009.07.035

19 Clark NV, Gujral HS, Wright KN. Impact of a fellowship-trained minimally invasive gynecologic surgeon on patient outcomes. JSLS 2017;21(03):e2017.00037. Doi: 10.4293/JSLS.2017.00037

20 Seymour NE, Gallagher AG, Roman SA, et al. Virtual reality training improves operating room performance: results of a randomized, double-blinded study. Ann Surg 2002;236(04):458-463, discussion 463-464. Doi: 10.1097/00000658-200210000-00008

21 Clavien PA, Barkun J, de Oliveira ML, et al. The Clavien-Dindo classification of surgical complications: five-year experience. Ann Surg 2009;250(02):187-196. Doi: 10.1097/SLA.0b013e3181b13ca2

22 Liceaga A, Fernandes LF, Romeo A, Gagstatter F. Romeo's gladiator rule: knots, stitches and knot typing techniques: a tutorial based on a few simple rules; new concepts to teach suturing techniques in laparoscopic surgery. 2nd ed. Schramberg: Endo Press; 2015.

23 Nácul MP, Cavazzola LT, de Melo MC. Current status of residency training in laparoscopic surgery in Brazil: a critical review. Arq Bras Cir Dig 2015;28(01):81-85. Doi: 10.1590/S0102-67202015000100020
24 Dilley SE, Straughn JM Jr, Leath CA III. The evolution of and evidence for opportunistic salpingectomy. Obstet Gynecol 2017; 130(04):814-824. Doi: 10.1097/AOG.0000000000002243

25 Viganò P, Parazzini F, Somigliana E, Vercellini P. Endometriosis: epidemiology and aetiological factors. Best Pract Res Clin Obstet Gynaecol 2004;18(02):177-200. Doi: 10.1016/j.bpobgyn.2004.01.007

26 Nakamura-Pereira M, Esteves-Pereira AP, Gama SGN, Leal M. Elective repeat cesarean delivery in women eligible for trial of labor in Brazil. Int J Gynaecol Obstet 2018;143(03):351-359. Doi: 10.1002/ijgo.12660

27 Ferreira H, van Belle Y, Tanos V, et al. Simulation and training of gynaecological skills. Facts Views Vis ObGyn 2018;10(01):21-27

28 Munz Y, Almoudaris AM, Moorthy K, Dosis A, Liddle AD, Darzi AW. Curriculum-based solo virtual reality training for laparoscopic intracorporeal knot tying: objective assessment of the transfer of skill from virtual reality to reality. Am J Surg 2007;193(06): 774-783. Doi: 10.1016/j.amjsurg.2007.01.022

29 Thuler FR, de Freitas WR Jr, Ilias EJ, Kassab P, Malheiros CA. Laparoscopic bariatric surgery training program model: gastric bypass. BMC Surg 2014;14:101. Doi: 10.1186/1471-2482-14-101

30 Mucksavage P, Lee J, Kerbl DC, Clayman RV, McDougall EM. Preoperative warming up exercises improve laparoscopic operative times in an experienced laparoscopic surgeon. JEndourol 2012;26(07):765-768. Doi: 10.1089/end.2011.0134

31 Asoğlu MR, Achjian T, Akbilgiç O, Borahay MA, Kılıç GS. The impact of a simulation-based training lab on outcomes of hysterectomy.J Turk Ger Gynecol Assoc 2016;17(02):60-64. Doi: 10.5152/jtgga.2016.16053

32 Korndorffer JR Jr, Stefanidis D, Scott DJ. Laparoscopic skills laboratories: current assessment and a call for resident training standards. Am J Surg 2006;191(01):17-22. Doi: 10.1016/j.amjsurg.2005.05.048

33 Nickel F, Kowalewski KF, Müller-Stich BP. [Risk awareness and training for prevention of complications in minimally invasive surgery]. Chirurg 2015;86(12):1121-1127. Doi: 10.1007/s00104-015-0097-6 